\title{
The Mechanism Causing an Increase in Farmland Transfer Rent and the Restraining Effect of High Rent on Grain Production
}

\author{
Hong Li $\mathbb{D}^{1,2}$ and Xian Zhang $\mathbb{D}^{1}$ \\ ${ }^{1}$ School of Economics, Sichuan University, Chengdu 610065, China \\ ${ }^{2}$ Department of Management Engineering, Anhui Communications Vocational and Technical College, Hefei 230051, China
}

Correspondence should be addressed to Xian Zhang; zxscu@126.com

Received 18 September 2021; Accepted 4 October 2021; Published 15 October 2021

Academic Editor: Daqing Gong

Copyright (c) 2021 Hong Li and Xian Zhang. This is an open access article distributed under the Creative Commons Attribution License, which permits unrestricted use, distribution, and reproduction in any medium, provided the original work is properly cited.

\begin{abstract}
The rent of farmland transfer represents the economic realization of farmland contracts and management rights of agricultural households. A three-stage dynamic game model with three players is constructed in this paper to study the mechanism causing an increase in farmland transfer rent. Based on the theory of producer equilibrium and production possibility boundaries, this paper studies the restraining effect of high rent on grain production and analyzes the factors that prevent the decline in grain production at present. Combined with the process of farmland transfer in a village, both the mechanism causing an increase in farmland transfer rent and the restraining effect of high rent on grain production are empirically analyzed. The conclusion is as follows: the basic direction of farmland transfer is from farmers with a low production capacity to farmers with a high production capacity, and the rent level is determined by the transferors with high production capacity; about half of the economies of scale profits and two-thirds of transferees' subsidies are converted into farmland transfer rents. High farmland transfer rent reinforces "nongrain" and "nonagricultural" behaviors. Finally, it is suggested that farmers should be given vocational training in agricultural production, "farmland transfer tax" should be levied on excessive farmland transfer rent, and transferees should be subsidized for grain production.
\end{abstract}

\section{Introduction}

The rent of farmland transfer refers to the land rent that the transferees [1] (who transfer farmland from peasants) paid to the transferors (the peasants who transfer out farmland) to obtain the management rights of farmland. It is a critical factor in ensuring the successful transfer of farmland in China. The introduction of a third right, a land management right, which is transferable from agricultural workers to outsiders, has enabled a huge land assembly movement, affecting millions of small holdings [2]. In recent years, the rent of farmland transfer has been rising. From 2005 to 2015, China's farmland transfer rate increased at an average annual rate of $20.53 \%$, while at the same time, the rent of farmland transfer increased at an average annual rate of $24.60 \%$, significantly faster than the speed of farmland transfer [3]. According to tuliu.com, in 2016 and 2017, the average farmland transfer rent of irrigated land in 13 major grain-producing provinces was CNY13 387.5 per ha, and it was as high as CNY24 000 per ha in some economically developed areas, significantly more than the reasonable rent level that grain production can bear.

High transfer rent leads to worry about the overcapitalization of farmland transfer and grain security. Scholars are aiming to study why the rent of farmland transfer continues to rise and what effects high farmland transfer rent have on grain production. This paper demonstrates the mechanism causing an increase in farmland transfer rent through dynamic game theory, analyzes the restraining effect of high farmland transfer rent on grain production by economic principles, and reveals the corresponding policy implications.

This paper is arranged as follows. Section 1 is the introduction, where we discuss the purpose of this paper. 
Section 2 is a literature review, which summarizes the relevant research literature in recent years and provides a brief review. Section 3 gives an explanation of model construction, which analyzes economics theory. Section 4 presents the model analysis from which conclusions can be drawn. In Section 5, we discuss the restraining effect on grain production, using the theory of economics to analyze the restraining mechanism and further considering the reasons why grain production did not decline in recent years. Section 6 presents the empirical analysis, which proves the successful application of our models to the process of farmland transfer in a village, and finally, conclusions and policy implications are given in Section 7 .

From our research, farmland transfer rent will continue to rise, and finally reduce the grain production; the reference for the decision-making can be revealed for the government, the transferors, and the transferees.

\section{Literature Review}

The research on farmland transfer rent is divided into two stages. The first stage is represented by research conducted around 2010, with scholars mainly focusing on the low rent of farmland transfer, the damage of famers' interests, and the poor situation of farmland transfer. The calculation model, composition, determinants, and formation mechanism of farmland transfer rent are focused on in the research, and their purpose is to improve farmland transfer rent, protect farmers' interests, and promote farmland transfer. Wang et al. [4] study show that $30 \%$ to $50 \%$ of transferred land does not receive any rent, both in terms of the number of land parcels and the land area. Zhang [5] and Zhai [6] built a calculation model of farmland transfer rent, analyzed the reasons for the low actual rental prices, and developed a theoretical basis and calculation model to improve farmland transfer rent. $\mathrm{Du}$ et al. [7], $\mathrm{Mu}$ et al. [8, 9], and $\mathrm{Lu}[10]$ analyzed the actual composition of farmland transfer rent from the perspectives of Marx's land rent theory, the composition of rent, and land development right and explored the neglected components of farmland transfer rent. Deng [11] and Shen et al. [12], respectively, studied the determinants of farmland transfer rent from the perspectives of transaction costs and resource endowment. Tian and Chen [13] and Cheng et al. [14] studied the formation mechanism of farmland transfer rent from the perspectives of rural ethical norms and behavioral science, emphasizing the influence of social factors on farmland transfer rent. Outside China, there are some scholars who also study farmland rental prices, such as Jacoby et al. [15] and Jin and Deininger [16], whose studies show that farmland transfer rental price is impacted by the frequency of land adjustments and the productivity of land.

After 2017, a rapid rise in farmland transfer rent received wide attention from scholars, who began to study the reasons for the high farmland transfer rent. Quan et al. [17] believe that the phenomenon of excessive farmland transfer rent is a manifestation of overcapitalization of farmland. The empirical study of Hou and Jiang [18] shows that the expected price of farmers increases the rental price of farmland transfer. Gong and Guo [19] believe that the farmland preference of industrial and commercial enterprises and the opportunity cost of farmland management are the crucial factors for the rigid increase in farmland transfer rental price. Zhu and Luo [3] found that farmers' "price illusion" of farmland leads to the failure of the price mechanism of farmland transfer rent. Gao [20] further suggests that the striking coupling between farmers' "price illusion" and tenants' "profit illusion" leads to the failure of price highly priced farmland transfer rent. Liu and Liu [21] built a game model, and believed that it was the households that refuse to transfer farmland in rural areas that increased the rent of farmland transfer. Based on the method of the price game, Zhang and Zhu [22] and Zhang et al. [23] found that the transferor of farmland raised the farmland transfer rent by taking advantage of knowing the details of the transferee's profit. Outside China, some scholars study the factors causing the rise of farmland rental prices, such as farmers' emotional attachment to farmland [24], the personified property characteristics of farmland [25], and the marginal contribution rate of agricultural subsidies to land rental price [26-29].

Scholars have studied the effect of operation scale and agricultural subsidies on the rent of farmland transfer. From the perspective of scale operation, there are more people and less land in China, and total profits are far lower than the normal level [30]. To increase the total profit of farmland operators, it is necessary to develop the scale operation of farmland. Zhong and Tang [31] used the classical theory of supply and demand to analyze the market of farmland transfer. The larger the operators' demand for the scale of farmland, the higher the farmland transfer rent [32-34]. Offfarm employment and part-time employment can significantly affect the scale of land transfer of farmers $[35,36]$. Shang et al. [37] studied the formation mechanism of farmland transfer rent under government-led farmland transfer and believed that government-led farmland transfer would lead to the multiplier effect of land rent, thereby amplifying the elasticity of demand and boosting the premium of farmland transfer. Du and Zhu [38] adopted the ESDA method and spatial econometric model to study the spatial-temporal evolution and the macro-differentiation mechanism of farmland transfer rent in China, thereby identifying the factors influencing rent increase and differentiation. The studies of Cao and Zhang [39] and Yang et al. [40] show that the larger the transferred area of farmland, the larger the operation scale, the higher the profit, and the more significant the income effect. From the perspective of rental price increased by agricultural subsidies, Wang et al. [41], Ma [42], and Liu [43] believe that the existing agricultural subsidies strengthen farmers' awareness of contract rights, use farmland as a tool to improve the welfare of contractors, and facilitate subsidy development, consequently increasing the transfer rental price of farmland. Zhong et al. [44], Sun [45], and Xu and Zhang [46] studied the distribution ratio of subsidies between transfer parties. Due to different research regions, times, and conditions, different conclusions were drawn. Outside China, some scholars also study the relationship between farmland 
rental prices and government subsidies, and they $[26,29,47,48]$ all suggest that government subsidies increase land rental price.

Scholars are worried that the abnormal rise in farmland transfer rent may have a negative impact on China's food security. Du and Xiao [49] believe that farmland transfer rent has a significant impact on the overall situation of sustainable agricultural development. Quan et al. [17] suggest that the transfer rent of farmland, which can cost more than CNY 15000 per ha, can never come from the profit of grain production but must come from the profit of nongrain and nonagricultural production. In reality, the farmland transfer rental price is becoming increasingly higher. Song and $\mathrm{Wu}[50]$ argues in his study that transferees would engage in nongrain production in order to reduce operational risks due to the increase in cost. Zeng [51] stated that the tendency of the "nongrain" and "nonagricultural" production is serious and progressing quickly. Wang and Lei [52] argued that, in the face of rising farmland transfer rental price, transferees may adjust the planting structure of crops, reducing the proportion of food crops and increasing the proportion of cash crops.

In the abovementioned research, scholars have studied the factors that hinder the increase in rent in the era of low rent and the factors that stimulate the rise in rent in the era of high rent, and they have even calculated the theoretically reasonable rent of farmland transfer through the economic model. However, these studies did not reveal the mechanism causing the increase in rent. Although some scholars have studied the effect of subsidies causing the increase in rent and even calculated the distribution ratio of subsidies between the transferor and the transferee, they have not theoretically clarified the mechanism and principle causing this increase in terms of subsidies. Scholars discussed their concerns about the impact of rising rent on food security but did not analyze the mechanisms of impact and the principle of economics. In this paper, three-stage complete information dynamic game theory is used to study the mechanism causing an increase in farmland transfer rental price, and the oligopoly model is used to determine this by examining scale economy and the transferee's subsidy. Thus, this paper supplements the lack of research on the mechanism causing an increase in farmland transfer rental price.

\section{Model Construction}

3.1. Basics of the Model. Under the household contract responsibility system, farmers equally distribute land in villages, and the spatial distribution of agricultural land is fragmented, partitioned, and highly dispersed. At the same time, due to the reasons of age, gender, education, and technology, the production capacity of farmers differs and presents a normal distribution. Farmers with a low production capacity are willing to transfer out farmland because they cannot gain agricultural profits, while farmers with a high production capacity are willing to transfer in farmland because they have excessive agricultural profits, so they are willing to expand the scale of agricultural production and gain more agricultural profits. As a result, the farmland transfer market is formed. The fragmented farmland is intermixed and randomly distributed, as shown in Figure 1.

In Figure 1, $A$ represents farmers of low production capacity, $B$ represents farmers of medium production capacity, and $C$ represents farmers of high production capacity. In addition to $A, B$, and $C, D$ represents the entities of higher production capacity outside the village. For the same farmland, farmers with a higher production capacity can generate higher profits than farmers with a lower production capacity. Therefore, farmers with a higher production capacity will transfer in farmland to obtain additional profits. The direction of farmland transfer is from farmers with a lower production capacity to farmers with a higher production capacity. In the negotiation between the transferors (who transfer out the farmland) and the transferees (who transfer farmland from the transferors), the transferors with different production capacities will receive different prices of rent. The higher the capacity, the more the profit, and the higher the rent. Therefore, the transferors with different production capacities determine the different rents of farmland transfer. In the process of transferring farmland from farmers with a low production capacity to those with a high production capacity, the rent of farmland transfer continues to rise with the increase of production capacity of transferors. In Figure 1, during the process of farmland transfer from $A$ to $B$ to $C$, and finally to $D$, the rent of farmland transfer rises with the increase in the production capacity of $B$ and $C$.

3.2. Hypothesis of the Model. It is necessary to make assumptions before building the model. We assume that there are gaps in the production capacity of farmers and that they possess a thorough understanding of each other's situation. $A$ represents farmers of low production capacity, whose agricultural profit is 0 , and $B$ represents farmers of medium production capacity, whose agricultural profit is $R$. $C$ represents farmers of high production capacity, whose agricultural profits are $R+a R$, as $C$ can obtain $a R(a>0)$ profits as well as $R$ (the profits of $B$ ). $D$ is an economic entity outside the village, whose profits are $R+a R+b R$, as $D$ can obtain $b R$ $(b>0)$ profits as well as $R+a R$ (the profits of $C$ ). In the negotiation between the transferors and the transferees, the transferors can receive the ideal rent based on the complete information of their respective benefits, and the transferees have to give up a portion of the operating profits and transform it into the rent of the transferors.

In the negotiation of farmland transfer, the two parties of the transfer establish the rent principle of sharing the excessive profits equally according to their own utility. Let $U_{\text {transferor }}$ and $U_{\text {transferee }}$ be the utilities of the transferors and the transferees of farmland, $T$ be the rent of farmland transfer, and $R_{\text {excessive }}$ be the excessive profit of the transferees of farmland. Assume that $U_{\text {transferor }}$ is a linear increasing function of $T$, that is, $U_{\text {tranferor }}=T, U_{\text {transferee }}$ is a linear increasing function of $R_{\text {excessive, }}$ and $U_{\text {transferee }}$ is also a linear decreasing function of $T$, that is, $U_{\text {transferee }}=R_{\text {excessive }}-T$. The result of the negotiation is that the utilities of both parties in the transfer of farmland is 


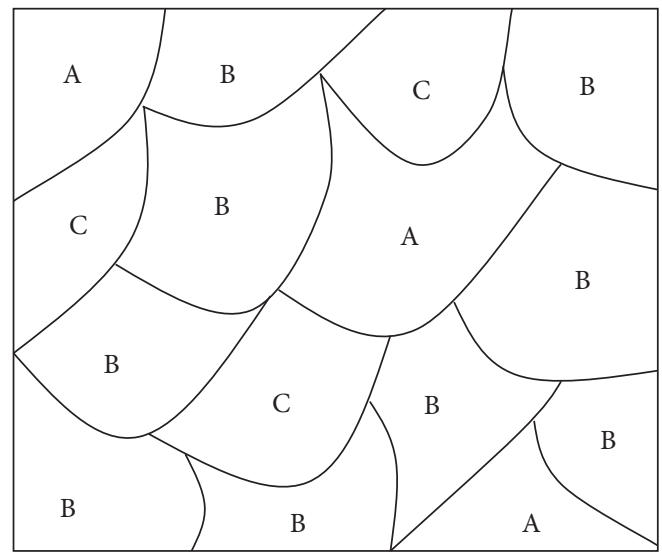

FIgURE 1: Abridged general view of farmland distribution in a village.

equal, that is, $U_{\text {transfer }}=U_{\text {transferee; }}$ thus, the rent of farmland transfer is half of the transferee's excessive profit, meaning that both parties in the negotiation share the transferee's excessive profit equally.

3.3. Model Construction. Based on the above analysis, according to the three-stage imperfect information dynamic game model of three players in the research of Xie [53], this paper constructs a three-stage complete information dynamic game model of three players to demonstrate that the rent of farmland transfer continuously rises with the increase in the production capacity of transferors. The game expansion form is shown in Figure 2.

Figure 2 reflects the transfer process of a piece of farmland from $A$ to $B$ to $C$, and finally to $D$, revealing the mechanism causing an increase in farmland transfer rent due to the increase in farmers' production capacity. In the figure, the three parties, $A, B$, and $C$, each have two strategies of "farming" and "transferring." The black dots represent game nodes, and the arrays at nodes represent the payoff of the transferees and the transferors. In the first stage, $A$ chooses the "farming" strategy, and there is no agricultural profit, so both the profits of transferee $B$ and transferor $A$ are zero. The game enters the second stage after $A$ completes its farmland transfer, where $B$ chooses the "farming" strategy and shares its excessive profits equally with $A$, so that transferee $B$ and transferor $A$ both have the payoff of $(R / 2)$. The game enters the third stage after $B$ completes its farmland transfer, and $C$ chooses the "farming" strategy. $C$ should pay $B$ 's agricultural profits, $R$, and share its excessive profits, $a R$, with $B$, so the payoff of transferee $C$ is $(a R / 2)$, and the payoff of transferor $B$ is $R+(a R / 2)$. If $C$ chooses the "transferring" strategy, the entity $D$ outside the village should pay $C$ 's agricultural profits, $R+a R$, and share its excessive profits, $b R$, with $C$; then, the payoff of the entity $D$ outside the village is $(b R / 2)$, and the payoff of the transferor $C$ is $R+a R+(b R / 2)$.

\section{Model Analysis}

4.1. Model Solving. Through the analysis of the game expansion form, according to the inverse induction method, in

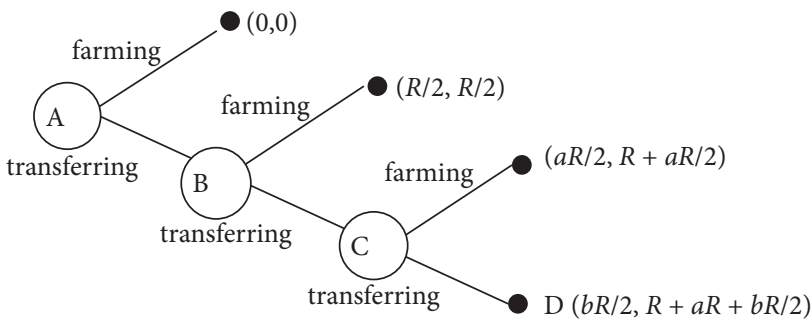

Figure 2: The expansion form of the game.

the third stage, $C$ has two strategies: "farming" and "transferring." If it chooses the "farming" strategy, the payoff of $C$ is $(a R / 2)$, and if it chooses the "transferring" strategy, its payoff is $R+a R+(b R / 2)$. Rational $C$ will choose the "transferring" strategy. Therefore, when back-stepping to the second and first stages, rationals $B$ and $A$ will also choose the "transferring" strategy and obtain the payoff $R+a R+(b R / 2)$. Thus, "transferring-transferring-transferring" is the equilibrium path of the three-stage dynamic game of the three players, and "transferring" is the equilibrium strategy of each player. After three stages of farmland transfer, the rent of one piece of farmland increases from $(R / 2)$ to $R+(a R / 2)$, and finally, to $R+a R+(b R / 2)$. The three stages and three rents prove that the rent of farmland transfer is determined by the different production capacities of the transferors.

The equilibrium path reveals the basic law that farmland is transferred from farmers with a low production capacity to those with a high production capacity, and the rent of farmland transfer continues to rise with the increase in production capacities of transferors.

With the promotion of the confirmation, registration, and certification of farmland, the contract and management rights of farmland becomes increasingly clearer. Contractors will not lose the interest of increasing rent with the transfer of management rights. On the contrary, contractors will gain the interest of increasing rent due to the clarity of the contract rights. Players $A$ and $B$ of the game, with their clear farmland contract rights, gain the rising rent of farmland transfer and finally receive $R+a R+(b R / 2)$ farmland transfer rent. 
4.2. Mechanism Causing an Increase in Rental Price by Scale Economy. By means of the Stackelberg model, this paper explains that the scale economy increases the rental price of farmland transfer. There are households $B_{1}, B_{2}, \ldots, B_{n}$ in $B$ with medium production capacity. It is assumed that $B_{1}$ and $B_{2}$ have the same production capacity, and $B_{1}$ has the advantage of scale economy over $B_{2}$. Because they possess complete awareness of each other's situation, $B_{1}$ transfers in farmland firstly and determines the optimal farmland scale and transfer rent under the condition of profit maximization, and $B_{2}$ can only transfer in farmland at the rent of $B_{1}$. Let $\pi_{1}$ and $\pi_{2}$ be the profit functions of $B_{1}$ and $B_{2}$, and $Q+q$, $Q$ be the unit income of $B_{1}$ and $B_{2}$. The farmland transfer rent, $T$, is an increasing function of the total area of the transferred farmland $N, T=\alpha+\beta N$. The area of the transferred farmland of $\mathrm{B}_{1}$ is $N_{1}$, and the area of the transferred farmland area of $\mathrm{B}_{2}$ is $N_{2}, N=N_{1}+N_{2}$.

$$
\begin{aligned}
& \pi_{1}=(Q+q) N_{1}-T(N) N_{1}, \\
& \pi_{2}=Q N_{2}-T(N) N_{2} .
\end{aligned}
$$

The inverse induction method is used to solve the perfect Nash equilibrium of the subgame of $B_{1}$ and $B_{2}$. Firstly, analyzing the reaction of $B_{2}$, who acts later than $B_{1}, B_{2}$ can only maximize its own profit under the condition of knowing the farmlands and rents of $B_{1}$. Substituting $N=N_{1}+N_{2}$ into equation (2), the optimal farmland scale of $B_{2}$ can be obtained as

$$
N_{2}=\frac{Q-\alpha-\beta N_{1}}{2 \beta} .
$$

Clearly, the optimal farmland scale of $B_{2}$ is a function of the farmland scale of $B_{1}$. $B_{1}$ knows the decision-making idea of $B_{2}$; before determining the farmland scale $N_{1}, B_{1}$ knows that the farmland scale $N_{2}$ would be determined according to equation (3). Therefore, by substituting the optimal farmland scale of $B_{2}$ into its profit formula (1), the farmland scale $N_{1}$ and transfer rent $T$ of $B_{1}$ can be obtained:

$$
\begin{aligned}
& N_{1}=\frac{Q-2 q-\alpha}{4 \beta}, \\
& T=\alpha+\beta N=\frac{3 Q+\alpha}{4}+\frac{q}{2} .
\end{aligned}
$$

In the same way, the farmland transfer rent, $T_{0}$, without scale economy, $q$, can be calculated:

$$
T_{0}=\alpha+\beta N=\frac{3 Q+\alpha}{4} .
$$

By comparing equation (6) with equation (5), scale economy, $q$, enters into the expression of farmland transfer rents, and it raises the rents of farmland transfer without an economy of scale about $(q / 2)$, proving that scale economy increases the rental price of farmland transfer. At this point, if $B_{2}$ 's farmland operating profit, $Q$, is less than the rent level $(3 Q+\alpha / 4)+$ $(q / 2)$ of farmland transfer, it will quit the competition of farmland transfer and even transfer its own farmland to $B_{1}$, which will not only allow it to obtain its own farmland operating profit, $Q$, but also some scale economy of $B_{1}$.
4.3. Mechanism Causing an Increase in Rental Price by Transferees' Subsidies. In order to promote farmland transfer and encourage farmland transferees to transfer more farmlands in from contractors for large-scale production, the government provides subsidies to transferees. Through the Cournot model, we prove that transferees' subsidies will partially convert into the rent and increase the price of farmland transfer rent.

There are households, $C_{1}$ and $C_{2}$, in $C$ with a high production capacity. Let $\pi_{1}$ and $\pi_{2}$ be the profit functions of $C_{1}$ and $C_{2}$. Their unit production capacities are equal, both are $Q$. The farmland transfer rent, $T$, is the linear increasing function of the total area of the transferred farmland $N$, $T=\alpha+\beta N$. The subsidy standard is $S$ per ha. The area of the transferred farmland of $C_{1}$ is $N_{1}$, and the area of the transferred farmland of $C_{2}$ is $N_{2}, N=N_{1}+N_{2}$.

$$
\begin{aligned}
& \pi_{1}=Q N_{1}-T(N) N_{1}+S N_{1}, \\
& \pi_{2}=Q N_{2}-T(N) N_{2}+S N_{2} .
\end{aligned}
$$

Let the respective first partial derivatives of $C_{1}$ and $C_{2}$ be 0 .

$$
\begin{aligned}
& \frac{\partial \pi_{1}}{\partial N_{1}}=(Q+S-\alpha)-\beta N_{2}-2 \beta N_{1}=0 \\
& \frac{\partial \pi_{2}}{\partial N_{2}}=(Q+S-\alpha)-\beta N_{1}-2 \beta N_{2}=0 .
\end{aligned}
$$

We solve the equation set consisting of equations (9) and (10), obtain $N_{1}$ and $N_{2}$, and determine $T$ :

$$
T=\alpha+\beta N=\frac{2 Q+\alpha}{3}+\frac{2 S}{3} .
$$

In the same way, the farmland transfer rent, $T_{1}$, of $C_{1}$ and $C_{2}$ is obtained when there is no subsidy:

$$
T_{1}=\frac{2 Q+\alpha}{3}
$$

By comparing equation (11) with equation (12), the transferees' subsidy $S$ enters into the expression of farmland transfer rent and raises the farmland transfer rent without a subsidy by $(2 / 3) S$, proving that the transferees' agricultural subsidy increases the price of farmland transfer rent.

4.4. Model Summary. Based on the above analysis, the basic conclusions of the models are as follows: the basic law of farmland transfer is that farmland is transferred from farmers with a low production capacity to those with a high production capacity, and the farmland transfer rent is determined by high production capacity transferors. This is because the farmers with a high production capacity must make up for the net profits of their self-farming before they transfer out the farmland. About half of the scale economy 
and two-thirds of the transferees' subsidies are converted into farmland transfer rents. Since farmers are thoroughly informed on each other's situation, especially those with the same production capacity, farmers with an economy of scale must give a portion of the profits of scale economy to the transferors before transferring in the farmland from the transferors with the same production capacity. Transferees' subsidies motivate transferees to transfer more farmland in, which makes them likely to transfer in farmland from farmers with a high production capacity, thereby causing an inevitable increase in the rental price of farmland transfer and transforming a portion of the transferees' subsidies into the rent of farmland transfer.

In addition to these basic conclusions, two inferences can be drawn from the model.

Firstly, different objects of transfer produce different farmland transfer rents.

The farmland transferred from $A$ to $B$ or $C$ will produce different transfer rents. According to the principle of sharing excessive profits equally between the two parties in the negotiation, $A$ transfers farmland to $B$ with a medium production capacity and obtains rents of $(R / 2), A$ transfers farmland to $C$ with a high production capacity and obtains rents of $(R+a R / 2)$, and $B$ transfers farmland to $C$ and obtains rents of $(R+a R / 2)$. Clearly, $R+(a R / 2)>(R+a R / 2)>(R / 2)$, and this inference shows that different locations and different objects of farmland transfer produce different transfer rents, and it also explains why there are different rents of farmland transfer in the same village.

Secondly, economies of scale make it possible to transfer farmland among farmers at the same level. In the assumption of no economy of scale, it is impossible for farmers with the same production capacity to transfer farmland to each other, because the profit is zero after paying the farmland transfer rent. However, with economies of scale, farmers with the same production capacity can also transfer farmland. For example, if $B_{1}$ and $B_{2}$ have the same production capacity and, in the condition of no scale economy, $B_{1}$ transfers in farmlands from $B_{2}$, the profit will be zero after paying rent equal to $B_{2}$ 's farming profits. Therefore, in the conditions of no scale economy, it is impossible for $B_{1}$ to transfer in farmlands from $B_{2}$. If $B_{1}$ knows its economies of scale and still has profits of scale economies after paying $B_{2}$ 's farmland transfer rent, $B_{1}$ will take the initiative to transfer in farmland from $B_{2}$, making it possible to transfer farmland among farmers with the same production capacity.

Most farmers do not understand the calculations of complex economic models, but farmers know where the profits come from, and they carefully increase the profit of their agricultural operations in various ways. For example, transforming some of their economies of scale and subsidies into farmland transfer rent to transfer in more farmlands from other farmers generates more profits.

\section{The Restraining Effect of High Rent on Grain Production}

5.1. Impact Mechanism. The rising rent of farmland transfer will inevitably affect grain production. The purpose of the transferees transferring farmland to engage in agricultural production is to maximize profits. The rising rent of farmland transfer affects the production decisions of transferees in cost and profit and then restrains grain production, as shown in Figure 3.

In Figure 3, on the one hand, the increase in rent changes the cost structure of farmland transferees. Through the production decision of grain production, the increase in rent moves the iso-cost line position of farmland transferees and reduces the equilibrium quantity of grain of farmland transferees, which leads to the decline of grain output. On the other hand, the increase in rent changes the profit structure of farmland transferees. By making product decisions between "grain product" and "nongrain product," the price comparative advantage between the two products is adjusted, and the production of "grain product" of farmland transferees is reduced, which leads to a decrease in grain output.

Producer equilibrium theory better explains how the change in cost structure affects the equilibrium quantity of producers. Different from the classical analysis, "capital" in the classical analysis is replaced by "farmland input," and "labor" in the classical analysis is replaced by "labor and production materials." The reason for this is that farmland cost has become the main cost for farmland transferees engaged in agricultural production, which facilitates analyzing how the changes in cost structure effect the grain production, as shown in Figure 4.

In Figure 4, the vertical axis represents the input of farmland, and the horizontal axis represents the input of labor and production materials. The line CC is the iso-cost line of the transferee's given investment, which is tangent to the iso-quantity line $Q$ at point $E$, which determines the equilibrium quantity, $Q$, of the transferee under the given investment. With the increase in farmland transfer rent, the quantity and quality of farmland investment decrease, and the farmland investment drops to the position of $C_{1}$. If the prices of labor and production materials remain unchanged, the iso-cost line turns to $C_{1} C$, lower than that of $C C$, and $C_{1} C$ is tangent to the lower iso-quantity line $Q_{1}$ at $E_{1}$, which determines the equilibrium grain quantity, $Q_{1}$, in the condition of high farmland transfer rent, and $Q_{1}$ is lower than $Q$. Therefore, with the increase in farmland transfer rent, the equilibrium grain quantity decreases. The iso-quantity line and iso-cost line better explain that the increase in farmland transfer rent will reduce grain production. 


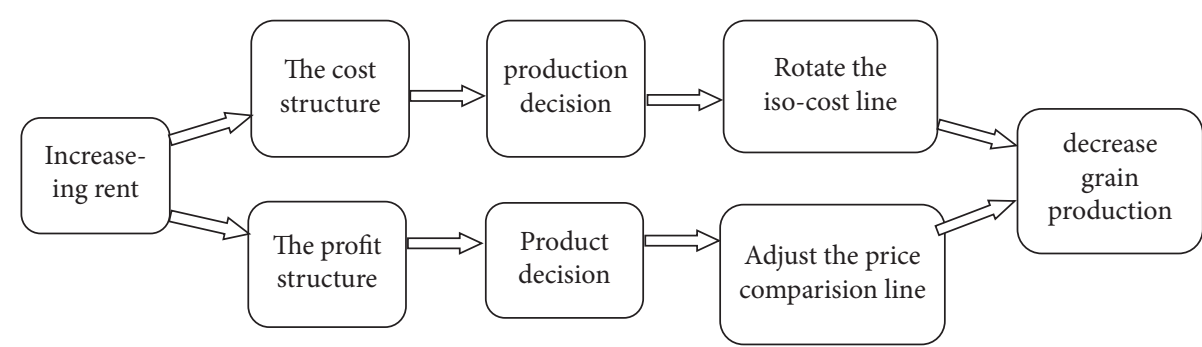

FIgURE 3: Abridged view of the impact mechanism on grain production by farmland transfer rent.

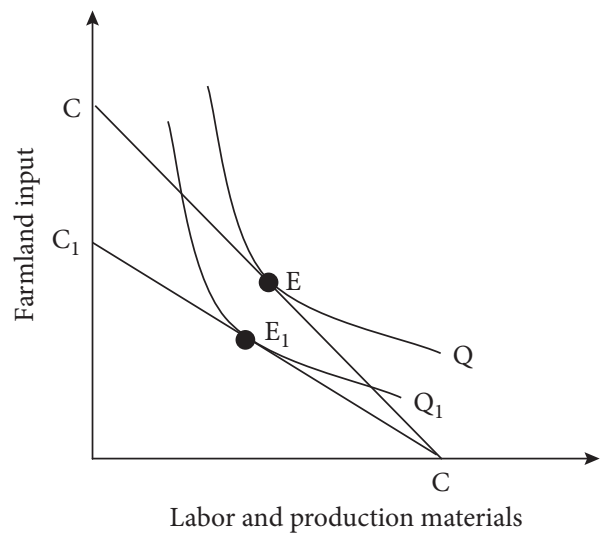

FIGURE 4: The impact of the increase in rent on grain production.

The increase in farmland transfer rent has changed the profit structure of transferees, making the profit of "grain product" lower than that of "nongrain product," forcing transferees to change the planting structure and use more farmlands to produce "nongrain product."

The theory of production possibility boundary explains how the change in profit structure leads to the change in planting structure. The farmland resources owned by the transferee can produce two kinds of products: "grain product" and "nongrain product." The $\mathrm{FF}^{\prime}$ line is the production possibility boundary of the two products, as shown in Figure 5.

In Figure 5, all the points on the production possibility boundary are efficient production combinations. The specific point of production combinations, that is, the amount of "grain products" and "nongrain products" that are produced, depends on the relative price ratios of "grain product" and "nongrain product." The marginal rate of transformation, $\mathrm{MRT}=P_{1} / P_{2}$, reflects the impact of the relative price ratio change between the two products on product decisions. $P_{1}$ is the price of "grain product," and $P_{2}$ is the price of "nongrain product." Under the lower farmland transfer rental price, the scale advantage of grain production is prominent, which brings more stable profits. The transferees choose point $A$ for production, with more "grain product" and less "nongrain product." With the increase in farmland transfer rent, the scale advantage of grain production is gradually lost, and the profit is reduced. In order to make up for the loss of profit, the transferee adjusts its planting structure, and MRT moves to point $F$ along the boundary of production possibility. Under the condition of high rent, $T$, the price of "nongrain product" at point $B$ is relatively high, MRTB $=\left(P_{1}-\mathrm{T}\right) /\left(P_{2}-T\right)<\mathrm{MRT}_{A}=P_{1} / P_{2}$, which brings more profits. The transferees choose point $B$ to produce more "nongrain product" and less "grain product." Therefore, the rise in farmland transfer rent forces transferees choosing "nonagricultural" or "nongrain" to reduce grain production.

5.2. Factors Preventing the Decline in Food Production. A question worthy of further consideration is that if, theoretically, the high farmland transfer rent leads to the decline in grain production, then why does China's grain production not decline significantly? Is the theory wrong? Or are there other forces at paly in maintaining the stability of grain production?

There are indeed several forces to stop the decline of grain production. The first force is the scale economy of grain production and the government subsidies for transferees. Although a portion of the profits of scale economy and the transferees' subsidies are converted into the farmland transfer rent of transferors, the other parts become the profits of transferees, which motivates big farm families to maintain grain production. The second force is the motivation of small farmers who maintain grain production to produce grains for their own purposes. The third force is that the small- and medium-sized transferees are between the breakeven point and the shutdown point and have not withdrawn from grain production. As shown in Figure 6, for many small- and medium-sized transferees, due to the large fixed costs, they insist on engaging in grain production as 


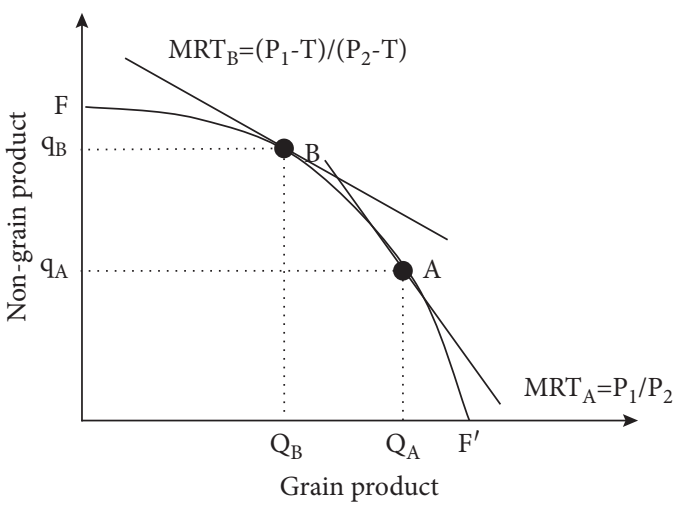

FIGURE 5: The increasing rental price causing an increase in nongrain production.

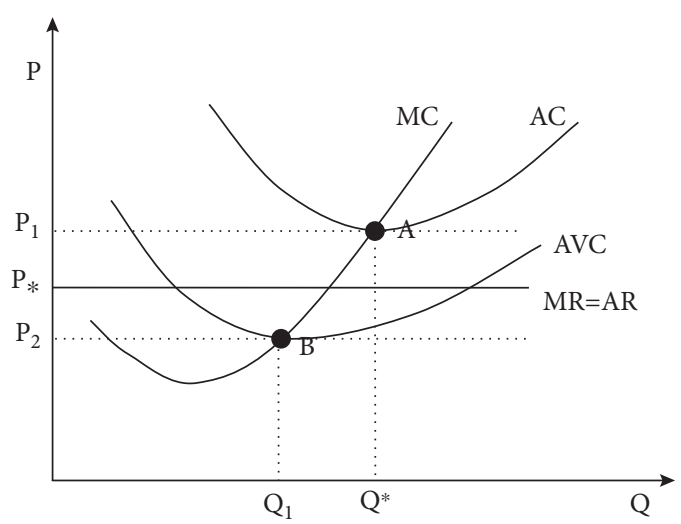

Figure 6: Food production decision under fixed input.

long as their farming profit is no less than point $B$ (i.e., the shutdown point), and even their net profits are negative so as to recover their fixed costs. Just as Marx said, "A certain number of small capitalists, determined by education, upbringing, tradition, competition and other conditions, have to invest their capital in agriculture as land leasing farmers, and they are forced to meet the profit below the average profit" [54]. The fourth force is the progress of agricultural science and technology, which has improved grain yield per ha. Grain yield per ha (the average of the three main grains) increased from $4161 \mathrm{~kg}$ in 2000 to $7030.5 \mathrm{~kg}$ in 2017 .

5.3. The Bidirectional Effect of Farmland Transfer Rent. High farmland transfer rent has a bidirectional effect. On the one hand, it strengthens farmers' willingness to transfer out of farmland, accelerates farmland transfer, and promotes the formation of large-scale production of farmland. On the other hand, it inhibits food production and affects national food security.

The above analysis shows that the high profit of "nongrain" and "nonagricultural" production induces transferees to transfer in farmland at high rent and engage in "nongrain" and "nonagricultural" production. The high rent of farmland transfer becomes a major factor that prevents transferees from returning to food production. As shown in Figure 5, once the transferee chooses to produce at point $B$, it is difficult for the transferee to return to point $A$ for production under the high farmland transfer rent, because point $B$ can bring higher profits and can pay higher rent, while point $A$ cannot. In this case, it is difficult to reverse the trend of "nongrain" and "nonagricultural" by using economic policies, such as grain production subsidies. The government must rely on administrative and legal means to curb the trend of "nongrain" and "nonagricultural."

\section{Case Analysis}

Village $\mathrm{G}$ is a natural village in Anhui Province. It is located in the northwest, about 40 kilometers of Hefei city, the capital of Anhui Province. It is located in the watershed between Yangtze River and Huaihe River and has a hilly landform, with a drop of about 20 meters. The village has a population of more than 150 people, and young and strong workers commute to the cities for work. Most of the villagers are left-behind old people and children, and the labor force is mainly composed of males in their $50 \mathrm{~s}$. The whole farmlands of the village have more than $33.3 \mathrm{ha}$, and they are relatively barren and highly dependent on chemical fertilizers. Farming mainly relies on small agricultural machinery, supplemented by manpower and medium-sized agricultural machinery, and farmland is mainly irrigated by water stored in ponds. The crops grow twice a year, mainly rice, wheat, and rapeseed. Rice is harvested in autumn, rapeseed is harvested in spring, and rice is planted in paddy fields, while wheat or rapeseed are planted in irrigated and sloping fields. The yield of rice is $4500-9000 \mathrm{~kg} / \mathrm{ha}$, that of wheat is $3750-6$ $750 \mathrm{~kg} / \mathrm{ha}$, and that of rapeseed is $1125-3000 \mathrm{~kg} / \mathrm{ha}$.

6.1. Distribution of the Production Capacity of Farmers. The production capacity of village $\mathrm{G}$ farmers can be divided into four levels. Yue and Guo, Ye, Hu and Shen, Peng, and Zhang form the production capacity echelon of the village, as shown in Table 1.

6.2. The Process of Farmland Transfer in Village G. Before the implementation of the policy of direct agriculture subsidy by the state, there was sporadic transfer of farmland, and the transferees paid agricultural tax and village reserves. After the implementation of direct agricultural subsidy policy, the transfer of farmland was once interrupted. Around 2008, the transfer of farmland rapidly rose again. The farmland transfer rent was calculated as rice in kind, and the agricultural subsidies directly paid to the contractors were owned by the contractors, not transferred with the farmland. The farmland transfer of village $\mathrm{G}$ can be roughly divided into four stages, as shown in Table 2.

6.3. Game Expansion Analysis of Village G's Farmland Transfer. Based on the above description of the farmland transfer process, the game expansion of farmland transfer in village $\mathrm{G}$ was formed, as shown in Figure 7.

The game expansion form of farmland transfer in village $G$ shows that after the three-stage dynamic game, the 
TABLe 1: The production capacity echelon in village G.

\begin{tabular}{lccccc}
\hline Name & Age & Education & Tools & Average production $(\mathrm{kg} / \mathrm{ha})$ & Echelon \\
\hline Yue & 73 & Lower primary school & Human and animal power & 6000 & Low \\
Guo & 70 & Lower primary school & Human and animal power & 6300 & Low \\
Ye & 60 & Primary school & Small machine and human power & 7500 & Low and medium \\
Hu & 50 & Junior high school & Small machine and human power & 8250 & Medium \\
Sheng & 50 & Junior high school & Small machine and human power & 8250 & Medium \\
Peng & 50 & Junior high school & Middle machine and human power & 8250 & Medium and high \\
Zhang & 50 & Junior high school & Industrial and commercial capital & Planting trees & The highest \\
\hline
\end{tabular}

Source: according to the author's survey, the age was calculated in 2014.

TABLE 2: Stages and rents of farmland transfer in village G. Measuring unit: $\mathrm{kg} / \mathrm{ha}$ (rice).

\begin{tabular}{lcccc}
\hline Stage & The direction of farmland transfer (the capacity of & Rent & $\begin{array}{c}\text { The } \\
\text { production) }\end{array}$ & The cause \\
\hline $\begin{array}{l}\text { The first stage } \\
\begin{array}{l}\text { The second } \\
\text { stage }\end{array}\end{array}$ & Low to low and medium & 525 & - & $\begin{array}{c}\text { The income of the contract right } \\
\text { The improvement of production } \\
\text { capacity }\end{array}$ \\
$\begin{array}{l}\text { The third stage } \\
\begin{array}{l}\text { The fourth } \\
\text { stage }\end{array}\end{array}$ & Low to medium & 825 & 300 & Scale economy \\
\hline
\end{tabular}

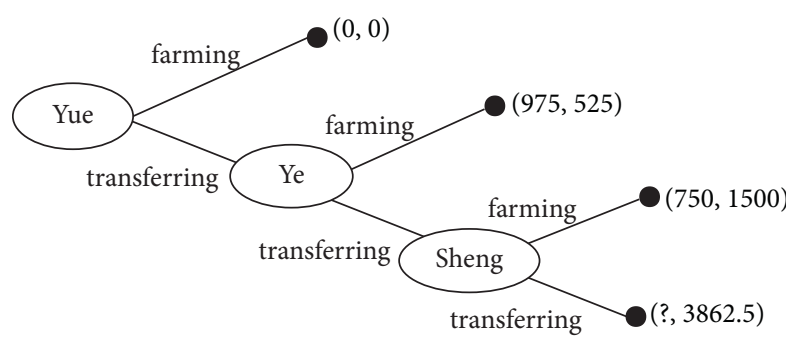

Figure 7: The expansion form of the game in village G (note: ? means that the benefit of Zhang, an industrial and commercial entity outside village $G$, is unknown).

farmland transfer rent increased from $525 \mathrm{~kg}$ rice per mu in the first stage to $3862.5 \mathrm{~kg}$ rice per ha in the fourth stage. The case of farmland transfer in village $G$ verifies the above model that we constructed, and the analysis is presented below.

Firstly, the basic direction of farmland transfer is from farmers with a low production capacity to farmers with a high production capacity, and the rent level is determined by the transferors with a high production capacity. The farmland was transferred from Yue with a low production capacity to Ye with medium and low production capacities, then from Ye to Shen with a medium production capacity, and finally to Zhang with the highest production capacity. In the process of farmland transfer, the rent of farmland transfer continues to rise, and each increment is determined by the transferors with higher production capacity. Yue, with low production capacity, determined that the lowest farmland transfer rent was $525 \mathrm{~kg}$ rice per ha. Ye, with low and medium production capacity, determined that the farmland transfer rent was $1500 \mathrm{~kg}$ rice per ha, while Shen, with a medium production capacity, determined that the farmland transfer rent was no less than $2250 \mathrm{~kg}$ rice per ha, which in fact was $3862.5 \mathrm{~kg}$ rice per ha. This is because the transferees must make up for the net self-farming profit of the transferors if transferring in the farmland of the transferors with a higher production capacity.

Secondly, about one-half of the scale economy profits are converted into farmland transfer rent. Before purchasing the medium-sized agricultural machinery, Peng only had small-sized agricultural machinery and transferred in 2.67 ha farmlands. Compared with Yue, the net yield per ha increased by $2250 \mathrm{~kg}$ rice. According to the farmland transfer rent of $825 \mathrm{~kg}$ rice per ha, the net profit per ha was $1425 \mathrm{~kg}$ rice, and the total profit was $3800 \mathrm{~kg}$ rice. After purchasing the medium-sized agricultural machinery and transferring in 7.33 ha farmlands, a total of 10 ha farmlands were acquired, and Peng gained a scale profit of $14,250 \mathrm{~kg}$ rice. However, the rent level increased from $825 \mathrm{~kg}$ rice per ha to $1500 \mathrm{~kg}$ rice, increasing by $675 \mathrm{~kg}$ rice, about $1 / 2$ of the scale profit; that is, $6750 \mathrm{~kg}$ rice was converted into farmland transfer rent.

Thirdly, the dilemma of transferees' subsidies must be discussed. In the process of farmland transfer, there are some difficulties; for example, farmers do not apply for government agricultural subsidies, and government agricultural subsidies do not play a strong role in promoting the farmland transfer. The agricultural subsidy policy of the local people's government of village $\mathrm{G}$ is as follows: annual payment of CNY 300 per ha if transferred in 6.67-33.33 ha farmland, and annual payment CNY 450 per ha if transferred in 33.33-66.67 ha farmland. Peng transferred in 10 ha farmland; thus, according to the policy, he can apply for CNY 3000 agricultural subsidies, but this subsidy failed to make up for the transferee's cost of application, leading Peng to give up on applying for agricultural 
subsidies. As such, this represents one of the dilemmas of transferee subsidies. If Peng transferred in all farmlands of 33.33 ha in village $G$, the minimum rent of farmland transfer would be $2250 \mathrm{~kg}$ rice per ha. According to the policy, he can apply for an annual agricultural subsidy of CNY 450 per ha, equivalent to $165 \mathrm{~kg}$ rice. Therefore, Peng's farming income per ha is zero, and his only income is the government's agricultural subsidies, $165 \times 33.33=5500 \mathrm{~kg}$ rice. When transferring in farmlands of 10 ha, Peng's income is $10 \times 750=7500 \mathrm{~kg}$ rice, which is higher than the income of all farmlands transferred in village G. Profit maximization forces Peng to decide against transferring in all the farmland of village G. Small transferees' subsidies cannot motivate transferees to further expand their scale of farmland, which is the second dilemma of transferee subsidies.

Fourthly, high rents restrain grain production. Zhang transferred in the farmland of the whole village at the rental cost of $3862.5 \mathrm{~kg}$ rice per ha, $1612.5 \mathrm{~kg}$ higher than the net profit of the farmers with a higher production capacity in the village. It is difficult to explain the rent of $1612.5 \mathrm{~kg}$ rice per ha with the scale economy of grain production and the transferee subsidies, and it can only be understood when considering the "nongrain" income of tree planting. The high profit of "nongrain" and "nonagricultural" production impels the transferee to pay high rent to transfer in more farmland. Meanwhile, the high farmland transfer rent also reinforces the "nongrain" and "nonagricultural" production of the transferees, making it difficult for them to return to grain production. Therefore, high farmland transfer rent is one of the decisive factors for transferees to give up grain production and engage in "nongrain" or "nonagricultural" production.

\section{Conclusions and Policy Implications}

This paper shows that the difference of production capacity among farmers determines the direction of farmland transfer; the basic direction of farmland transfer is from farmers with a low production capacity to farmers with a high production capacity. The farmland transfer rent must be able to make up for the operating profit of the transferors in order to make them transfer out farmlands. Therefore, the rent level is determined by the transferors with a higher production capacity. The scale economy of farmland and the government's agricultural subsidies to the transferees motivate the transferees to demand the scale of farmland operation and to transfer in the farmland of farmers with a higher production capacity, so that a portion of the scale economy profits and the transferees' subsidies are converted into the transfer rent of farmland. The high rent of farmland transfer does not come from the profit of grain production but from the profit of "nongrain" and "nonagricultural" production, which restrains grain production.

Based on the above conclusions, there are three policy implications:
Firstly, training farmers' skills of agricultural production should be strengthened. A total of $60 \%$ of the contracted land in China has not been transferred, which means that most of the farmlands are still farmed by contractors. The production capacity determines the direction of farmland transfer, and the rent level is determined by the transferors with a higher production capacity, which means that the higher the production capacity, the higher the yield, and the higher the rent level. We also recommend strengthening the training of farmers' skills of agricultural production and improving their production capacity, which will not only improve farmers' grain production and stabilize national grain production but also increase farmers' farmland transfer rents and increase their property incomes.

Secondly, we should timely introduce the "farmland transfer tax." The research of this paper shows that the excessive high rent of farmland transfer must come from the income of "nongrain" and "nonagricultural" production. The excessive high rent of farmland transfer will eventually reduce the farmlands for grain production, restrain the increase in grain production, and even reduce grain production. In terms of policy, referring to the "income tax" of capital gains, we should timely levy tax on the excessive high rent of farmland transfer, which can not only restrain the rapid rise in farmland transfer rent but also make up for the shortfall of financial resources caused by the government's agricultural subsidies.

Thirdly, we recommend the timely introduction of the policy of grain production subsidies for transferees. We should change the inflexible and single subsidy policy, reduce the subsidies for "nongrain" and "nonagricultural" production, and increase the subsidies for grain production of transferees. This will not only motivate transferees to expand the scale of farmland but will also restrain the tendency of "nongrain" and "nonagricultural" production so as to ensure stable and high grain production in China. Although there is no sign of a decline in grain production at the macro-level, it does not mean that this danger does not exist. At present, the central government has not yet issued a subsidy scheme for grain production of transferees. Now, we should focus on the object, methods, and scope of the subsidy policy for grain production of transferees so as to timely introduce the subsidy policy for grain production of transferees.

\section{Data Availability}

The data used to support the findings of this study are available from the corresponding author upon request.

\section{Conflicts of Interest}

The authors declare that they have no conflicts of interest regarding the publication of this paper. 


\section{Acknowledgments}

This research was supported by "Graduate Student's Research and Innovation Fund of Sichuan University" (Grant no. 2018YJSY019) and "Anhui Humanities and Social Science Research Project for Colleges and Universities 2019” (Grant no. SK2019A0925).

\section{References}

[1] H. Li and X. Zhang, "The equilibrium mechanism of interest distribution in farmland transfer: based on the perspective of the three-party game," Discrete Dynamics in Nature and Society, vol. 2021, Article ID 7912554, 12 pages, 2021.

[2] C. Zhou, Y. Liang, and A. Fuller, "Tracing agricultural land transfer in China: some legal and policy issues," Land, vol. 10, no. 1, p. 58, 2021.

[3] W. Y. Zhu and B. L. Luo, "Rural land price illusion: farmland market failure triggered by differences in value evaluation-an analysis based on survey data from 9 provinces," China Rural Survey, vol. 5, pp. 71-81, 2018.

[4] Y. Wang, L. Xin, H. Zhang, and Y. Li, "An estimation of the extent of rent-free farmland transfer and its driving forces in rural China: a multilevel logit model analysis," Sustainability, vol. 11, no. 11, p. 3161, 2019.

[5] Z. H. Zhang, "Study on the price of rural land transfer based on income present value method," Journal of Central University of Finance \& Economics, vol. 12, pp. 58-62, 2013.

[6] Y. N. Zhai, "Study on the circulation price of rural land contract and management right," Issues in Agricultural Economy, vol. 11, pp. 82-86, 2013.

[7] L. J. Du, Y. X. Zhao, and W. Ren, "Application of Marx's theory of land rent in land transfer pricing," Agricultural Economy, vol. 4, pp. 55-57, 2010.

[8] S. L. Mu, Y. F. Zhang, J. H. Gao, and C. L. Liu, "Transferring price of land contract and management rights at village levels," Resources Science, vol. 33, no. 5, pp. 923-928, 2011.

[9] S. L. Mu, Y. F. Zhang, and K. Y. Wang, "Agricultural land contract and management rights: transferring price and countermeasures in typical agricultural areas of China," Journal of Resources and Ecology, vol. 3, no. 3, pp. 262-268, 2012.

[10] J. Lu, "Discussion on the transfer price of the rights to land contractual management," Journal of Anhui Agricultural Sciences, vol. 38, no. 34, pp. 19661-19662, 2010.

[11] D. C. Deng, "Study on transaction cost and price of farmland transfer-analysis on the determinants of farmland transfer price," Research on Financial and Economic Issues, vol. 9, pp. 89-95, 2007.

[12] Y. Shen, S. B. Zhu, Y. Deng, L. Y. Teng, and R. R. Zhao, “An analysis of the factors of the price of farmland use rights' circulation-the experience from farmers and regional level," China Rural Survey, vol. 3, pp. 2-17, 2012.

[13] X. H. Tian and L. Chen, "How to determine the land rent?-a sociological study of formation mechanism of land circulation price," China Rural Survey, vol. 6, pp. 2-12, 2013.

[14] J. Cheng, X. B. Kong, J. Li, and X. L. Zhang, "The relationship between substitution degree of farmland social insurance function and farmland transfer-based on 330 peasant household surveys on the Jingji plains," Resources Science, vol. 34, no. 1, pp. 17-25, 2014.

[15] H. G. Jacoby, G. Li, and S. Rozelle, "Hazards of expropriation: tenure insecurity and investment in rural China," The
American Economic Review, vol. 92, no. 5, pp. 1420-1447, 2002.

[16] S. Jin and K. Deininger, "Land rental markets in the process of rural structural transformation: productivity and equity impacts from China," Journal of Comparative Economics, vol. 37, no. 4, pp. 629-646, 2009.

[17] S. W. Quan, L. F. Hu, Y. C. Zeng, and Y. Zhu, "The overcapitalization of land resources in rural China," Chinese Rural Economy, vol. 7, pp. 2-18, 2018.

[18] K. Hou and Y. S. Jiang, "The formation mechanism of the expected price of farmland transfer and its effect on the actual transfer price-empirical analysis of farmers in Chengdu economic zone," Rural Economy, vol. 9, pp. 19-24, 2017.

[19] B. B. Gong and Q. H. Guo, "Rural land rent at present: levels, influencing factors, and their effects," Rural Economy, vol. 3, pp. 24-32, 2019.

[20] J. S. Gao, "Price failure in rural land transfer: explanation and influence," Truth Seeking, vol. 6, pp. 92-106, 2019.

[21] L. H. Liu and Y. Liu, "A game-theory based research in the family farm to realize land moderate scale management: China population," Resources and Environment, vol. 28, no. 9, pp. 150-157, 2018.

[22] Y. Zhang and K. Zhu, "Study on the price of management right transfer of agricultural land under the "separation of three rights"-based on an analysis of price game," Price: Theory and Practice, vol. 8, pp. 77-81, 2018.

[23] B. Z. Zhang, Y. X. Ding, and H. T. Wang, "Study on the pricing of farmland management right under the mode of leasing," Jianghuai Tribune, vol. 4, pp. 26-31, 2019.

[24] J. L. Pierce, T. Kostova, and K. T. Dirks, “The state of psychological ownership: integrating and extending a century of research," Review of General Psychology, vol. 7, no. 1, pp. 84-107, 2003.

[25] A. A. Alchian and S. Woodward, "Reflections on the theory of the firm," Institutional Theoretical Economics, vol. 143, no. 1, pp. 110-136, 1991.

[26] E. Barrett and J. Michael, "Who really benefits from agricultural subsidies? evidence from field-level data," American Journal of Agricultural Economics, vol. 98, no. 4, pp. 1095$1113,2016$.

[27] L. Latruffe and C. L. Mouël, "Capitalization of government support in agricultural land prices: what do we know?" Journal of Economic Surveys, vol. 23, no. 4, pp. 659-691, 2009.

[28] M. J. Roberts, B. Kirwan, and J. Hopkins, "The incidence of government program payments on agricultural land rents: the challenges of identification," American Journal of Agricultural Economics, vol. 85, no. 3, pp. 762-769, 2003.

[29] E. Barrett, "The incidence of US agricultural subsidies on farmland rental rates," Journal of Political Economy, vol. 117, no. 1, pp. 138-164, 2009.

[30] S. A. Huang, D. M. Guo, and J. Wu, "An evaluation of the effects of direct grain subsidy policy," Chinese Rural Economy, vol. 1, pp. 17-31, 2019.

[31] L. Zhong and X. W. Tang, "An equilibrium analysis on the market for the circulation of farmlands," Chinese Journal of Management Science, vol. 17, no. 4, pp. 141-147, 2009.

[32] J. A. Juliano and G. Maitreesh, "Can unobserved heterogeneity in farmer ability explain the inverse relationship between farm size and productivity," Economics Letters, vol. 80, pp. 189-194, 2003.

[33] S. Maru and R. Marcel, "Impacts of large-scale farming on local communities' food security and income levels-empirical evidence from Oromia region, Ethiopia," Land Use Policy, vol. 47, pp. 282-292, 2015. 
[34] K. Deininger, S. Jin, F. Xia, and J. Huang, "Moving off the farm: land institutions to facilitate structural transformation and agricultural productivity growth in China," World Development, vol. 59, pp. 505-520, 2014.

[35] K. Huang, X. Deng, Y. Liu, Z. Yong, and D. Xu, "Does offfarm migration of female laborers inhibit land transfer? evidence from Sichuan province, China," Land, vol. 9, no. 1, p. $14,2020$.

[36] D. D. Xu, Z. L. Yong, X. Deng, L. Zhuang, and C. Qing, "Rural-urban migration and its effect on land transfer in rural China," Land, vol. 9, no. 1, p. 81, 2020.

[37] X. D. Shang, Q. Chang, and S. Q. Wang, "Study on price mechanism and policy effect of government-dominated rural farmland management rights' transfer," China Population, Resources and Environment, vol. 26, no. 8, pp. 116-124, 2016.

[38] T. Du and D. L. Zhu, "Studies on the spatio-temporal evolution and macro-mechanism of land circulation price in China," Resources Science, vol. 40, no. 11, pp. 2202-2212, 2018.

[39] R. F. Cao and A. L. Zhang, "Analysis on economic benefits of farmland transfer in central China: based on the survey of 313 peasant households of 27 villages in Hubei province," China Land Sciences, vol. 29, no. 9, pp. 66-72, 2015.

[40] Z. Yang, X. L. Ma, P. X. Zhu, and D. Ma, "Land transfer and income change of peasants," China Population, Resources and Environment, vol. 27, no. 5, pp. 111-120, 2017.

[41] Y. Y. Wang, Y. Y. Cai, and L. L. Zhu, "Analysis on regional effect of agricultural subsidy policy and its influencing factors-a case study in Wuhan, Jingmen, and Huanggang of Hubei province," Journal of Huazhong Agricultural University (Social Science Edition), vol. 1, pp. 8-15, 2017.

[42] L. H. Ma, "Farmland as welfare: practice mechanism, consequence presentation and its optimized path: analysis based on di village in Shanghai Suburb," Journal of Nanjing Agricultural University, vol. 13, no. 6, pp. 66-73, 2013.

[43] C. L. Liu, "Agricultural subsidies involvement: scale management and land rent dilemma," Journal of Fujian Provincial Committee Party School of CPC (Fujian Academy of Governance), vol. 5, pp. 131-139, 2019.

[44] P. N. Zhong, H. J. Gu, and Y. Q. Ji, "The role differentiation of farmers and the income distribution effect of agricultural subsidy policy-an empirical study on the income distribution effect of agricultural tax reduction and grain direct subsidy in Jiangsu province," Management World, vol. 5, pp. 65-70, 2008.

[45] P. Sun, "An empirical analysis of the income distribution effect of agricultural subsidy policy-Heilongjiang province as an example," Study and Practice, vol. 10, pp. 53-60, 2014.

[46] N. Xu and L. Q. Zhang, "Who really benefits from agricultural subsidies? - an empirical evidence based on income distribution effect of direct subsidy in agriculture," Journal of HIT(Social Sciences Edition), vol. 20, no. 4, pp. 134-140, 2018.

[47] N. Hendricks, J. Janzen, and K. Dhuyvetter, "Subsidy incidence and inertia in farmland rental markets: estimates from a dynamic panel," Journal of Agricultural and Resource Economics, vol. 37, no. 3, pp. 361-378, 2012.

[48] P. Ciaian and D. A. Kancs, "The capitalization of area payments into farmland rents: micro evidence from the new EU member states," Canadian Journal of Agricultural Economics/ Revue Canadienne D'agroeconomie, vol. 60, no. 4, pp. 517540, 2012.

[49] Z. X. Du and W. D. Xiao, "Agricultural scale management: status quo, problem and policy choice," Jianghuai Tribune, vol. 4, pp. 11-28, 2019.
[50] G. Song and J. Y. Wu, "Reason analysis and policy adjustment of "non-grain" in the farmland contracting and management right transfer," Academic Exchange, vol. 7, pp. 122-126, 2016.

[51] F. S. Zeng, "Establishment the incentive and restraint mechanisms for food security through agricultural land rental," Issues in Agricultural Economy, vol. 1, pp. 15-23, 2015.

[52] S. G. Wang and H. Lei, "The research on the impact of land transference costs rising on grain production-based on the adjustment of planting structure, adjustment of crops and substitution of production factors," Chinese Journal of Agricultural Resources and Regional Planning, vol. 40, no. 7 , pp. 58-65, 2019.

[53] S. Y. Xie, Games for Economics, Fudan University Press, Shanghai, China, Forth edition, 2017.

[54] M. Karl, Das Capital: The Third Volumep. 706, Second edition, People's Publishing House, Beijing, China, 2004. 